\title{
Cesarean section by maternal request
}

\section{Cesariana a pedido materno}

Raphael Câmara", Marcelo Burlä 2,3 , José Ferrari ${ }^{4}$, Lana Lima ${ }^{5}$, Joffre Amim Junior ${ }^{5}$, Antonio Braga ${ }^{2,5}$, Jorge Rezende Filho 5.

\begin{abstract}
A B S TR A C T
Cesarean section by maternal request is the one performed on a pregnant woman without medical indication and without contraindication to vaginal delivery. There is great controversy over requested cesarean section. Potential risks include complications in subsequent pregnancies, such as uterine rupture, placenta previa and accreta. Potential benefits of requested cesareans include a lower risk of postpartum hemorrhage in the first cesarean and fewer surgical complications compared with vaginal delivery. Cesarean section by request should never be performed before 39 weeks.
\end{abstract}

Keywords: Pregnant Women. Parturition. Cesarean Section.

\section{INTRODUCTION}

$T^{\mathrm{h}}$ he phenomenon of rising cesarean rates is registered in most countries of the world'. In Brazil, according to recent data published by the Ministry of Health, the percentage of cesarean deliveries is $40 \%$ in the public network, reaching $84 \%$ in the health-insured population ${ }^{2}$. In fact, one can observe an increasing rate of cesarean sections in Brazil in the last three decades, followed closely by a significant decrease in maternal mortality ${ }^{3}$.

The improvement in this indicator is due to a multitude of social and economic factors, as well as the improvement of the general health conditions of the population. On the other hand, it is still controversial whether the increase in caesarean section rates is also responsible for the decrease in maternal and perinatal morbidity and mortality. Studies show that, up to a certain level, maternal and perinatal mortality decreases due to the inclusion of patients who really need the caesarean section; and, from a certain point on, there may even be a worsening in such health indicators ${ }^{4}$. On the other hand, there are results that show that the increase in caesarean section rates does not relate to increased maternal mortality, which would permit to extend the procedure's indications, allowing even to perform a Caesarean at the patient's request ${ }^{5}$.

The subject of this paper is to review the medical indications for cesarean section, analyzing the impact of the delivery mode on mother and baby, as well as the ethical and bioethical implications of the cesarean section by request.

We performed the search in three databases: Medline, Scielo and Lilacs. We used the following key words: cesarean-section (and its derivations) and maternal-request [MeSH]. We limited the search to studies conducted in humans and published in English, Portuguese, Spanish and French in the period from 1966 to 2015. We also used the reference lists of the selected articles.

\section{MEDICAL INDICATIONS FOR CESAREAN SECTION}

As a rule, the cesarean section indications can be grouped between maternal and fetal, as well as in absolute and relative. Generically, cesarean sections indications are: active herpes at the time of labor; warts or other tumors that prevent the progression of fetal presentation; dystocia, which can be of shoulder, by cephalopelvic disproportion, fetal macrosomia or breech presentation; twin pregnancy (taking into account gestational age and presentation); infection by the human

1 - Institute of Gynecology, Federal University of Rio de Janeiro, Rio de Janeiro, RJ, Brazil. 2 - Department of Maternal and Child Care, Faculty of Medicine, Federal Fluminense University, Niteroi, RJ, Brazil. 3 - Society of Gynecology and Obstetrics of the State of Rio de Janeiro, Rio de Janeiro, RJ, Brazil. 4 - Federal University of Rondônia, Porto Velho, RO, Brazil. 5 - Department of Obstetrics, School of Medicine, Federal University of Rio de Janeiro, Rio de Janeiro, RJ, Brazil. 
immunodeficiency virus (depending on viral load and conditions related to labor); placenta accreta; central placenta previa; umbilical cord prolapse; fetal distress and premature placental detachment if the cesarean is the fastest mode of delivery; vasa previa detected before labor; and others ${ }^{6}$.

Due to the peculiarities of the issues under consideration, few are the outcomes for which there are randomized controlled trials pointing to the best mode of delivery. Among these, based on clinical trials, the breech delivery has advantages when carried out by Caesarean section, determining lower neonatal mortality ${ }^{7}$. Similarly, fetal macrosomia is one cesarean indication, since it involves increased morbidities, mainly neonatal. In this scenario, however, the question remains of what would be cutting weight measured by ultrasound that makes the cesarean delivery route most appropriate. The Project Guidelines of the Brazilian Medical Association shows that the macrosomic newborn is defined as one with birth weight higher than $4.000-4.500 \mathrm{~g}$, this definition being variable. But it is known that when the birth weight is greater than $4.000 \mathrm{~g}$, there is increased perinatal morbidity ${ }^{8}$.

Contrary to common sense, hypertensive disorders and their complications such as eclampsia are not, per se, absolute indications for cesarean sections and should be evaluated according to most recent robust evidence ${ }^{9}$. Similarly, past cesarean does not set a new indication for cesarean section. There is a small increased risk of uterine rupture during labor in these patients, but this must be weighed against other factors, notably the number of previous cesarean sections, the type of hysterectomy and the interval between the last cesarean section and the current labor.

\section{WHAT IS THE BEST DELIVERY ROUTE?}

From an epidemiological point of view, it is a difficult task to determine the best mode of delivery. This comes from intrinsic shortcomings of studies evaluating the subject, due to research designs, the number of participants involved, lack of clinical trials on delivery routes for cephalic fetuses at term, the great ideological potential of the researchers involved in this issue and the obvi- ous ethical implications in such studies involving pregnant women and fetuses.

We should also note a large bias in these studies on the delivery route, which is no distinction between the cesarean section performed during labor from the elective caesarean sections. It is remarkable and commendable, when comparing the risks of vaginal delivery and caesarean sections for both the mother and the fetus, that one separates "emergency" caesareans from elective ones - the object of analysis of this review.

The population-based study sponsored by the World Health Organization illustrates this issue. It evaluated over a hundred thousand births, demonstrating that the elective caesarean section, made without medical indication, before starting labor, has a protective effect in relation to maternal death, hysterectomies, neonatal death and perinatal morbidity and mortality joint index when compared with vaginal delivery. It is also worth mentioning that the study divided patients presenting with vaginal delivery and operative vaginal delivery, and in the latter, the numbers were higher for most of the negative outcomes. There is no way to separate the risks of operative vaginal delivery from the risks associated with vaginal delivery. There was no maternal and neonatal death associated with caesarean section without medical indication preceding labor, and it showed to prevent fetal deaths ${ }^{10}$. Unreasonably, in the conclusion the authors report that cesarean section should only be performed if medically indicated, contrary to the results presented

On the same theme, another population-based study that analyzed 286,565 births in 24 countries concluded that all other forms of birth bring greater risks compared with vaginal delivery, when taken as references ICU admissions, blood transfusions and hysterectomies. The conclusion is that cesarean section was associated with an increased inherent risk of serious complications for the mother, and caesareans should be performed only when there are clear benefits to justify the high cost of the procedure. It is prudent to point out that there was no maternal deaths recorded in elective cesarean sections without medical indication ${ }^{11}$. The work cited is obviously subject to criticism because of the difficulties of making 
homogeneous and reliable the information collected in 24 different countries, which invariably have different levels of complexity in the registration information from medical records.

A document by the American College of Gynecologists and Obstetricians in 2013 published guidelines for the cesarean section by request, which should only be performed after 39 weeks of gestation, never being done due to the absence of effective pain control mechanisms, and should be avoided in women who manifest a desire for numerous offspring. The review showed that, when compared with vaginal delivery, cesarean section by request showed a greater maternal length of hospital stay, a greater chance of neonatal respiratory problems (an issue only seen up to 39 weeks, with substantial improvement at 40 weeks or more), and a higher risk of complications such as hysterectomies and placenta accreta in subsequent pregnancies. On the other hand, elective cesarean section showed a lower rate of transfusions, bleeding, fewer surgical complications (vaginal delivery may require the use of forceps or emergency caesarean section), and lower chance of urinary incontinence in the first year postpartum and fetal brachial plexus injuries. Finally, and given the current level of knowledge, one cannot certify the superiority of a delivery route over another as regards to pain after delivery, pelvic pain, postpartum depression, fistulas and maternal mortality.

The only meta-analysis on the subject to date by Cochrane found no clinical trial comparing vaginal delivery with cesarean section at request ${ }^{12}$. A composite systematic review of 54 studies evaluating the various outcomes found most studies with low methodological quality, preventing robust conclusions. The results of greater consistency associate cesarean sections with increased risk of placenta previa in future pregnancies, increased maternal hospitalization time, respiratory morbidity of the newborn (which decreases with gestational age at which the surgery is done) and less risk of bleeding and blood transfusion ${ }^{13}$.

Very similar results have been shown in the review article published in the prestigious Journal of the American Medical Association. Cesarean section is associated with less perineal and operative injuries, bleeding, urinary and fecal incontinence, neonatal hypoxic-ischemic encephalopathy, neonatal asphyxia and brachial plexus injury when compared with vaginal delivery. No differences were found for maternal mortality, pain, postpartum and breastfeeding. Cesarean section showed unfavorable results for the occurrence of infections (certainly smaller in elective cesarean sections in relation to emergency ones), maternal hospital stay, uterine rupture in subsequent pregnancies and placenta previa / accreta in subsequent pregnancies ${ }^{14}$.

Similar guidelines are part of the current British protocol of the National Institute of Clinical Excellence, reporting less abdominal and perineal pain during childbirth and up to three days, vaginal injuries, early postpartum hemorrhage and shock in patients undergoing cesarean section when compared with those delivering vaginally. On the other hand, vaginal delivery is associated with shorter hospital stay, lower hysterectomy rates for postpartum hemorrhage and cardiac arrest ${ }^{15}$. A German prospective cohort study of more than 2500 women compared the two delivery routes in relation to a grouping of five associated outcomes (ICU stay, uterine rupture, eclampsia, severe obstetric hemorrhage and Miscellaneous) and cesarean section, both elective and emergency, showed worse results than the vaginal delivery ${ }^{16}$.

Data for the year 2013, published in 2015 by the American agency of health statistics, covering $90 \%$ of occurred births, showed that cesarean section was more associated with blood transfusion and admission to ICU than vaginal delivery and there were higher rates of uterine rupture and hysterectomies in patients undergoing multiple caesareans ${ }^{17}$. However, a retrospective cohort study that evaluated more than 80,000 births between 1993 and 2012 showed that the increase in cesarean rates in this period was associated with lower rates of damage to the brachial plexus and neonatal encephalopathy and there were no differences in accretion and hysterectomy in cesarean sections. The severe neonatal morbidity rate decreased three to five times in that period. It is noteworthy that even in scenarios where the caesarean rates are higher than $20 \%$, there was no difference in these results. There was only one case of maternal death in that period, which occurred in a vaginal delivery ${ }^{18}$. 
The lack of clinical trials comparing cesarean section with vaginal delivery in cephalic fetuses is remarkable. A strategy to promote such studies would be the analysis of groups according the intended delivery mode; even considering that the type of delivery was another, the result would go to the mode chosen at the beginning of the study. In this perspective, a study that evaluated more than 4000 births showed that vaginal delivery was more associated with the presence of meconium, and cesareans, more associated with fetal admission in NICU. There were no differences in neonatal respiratory and neurological morbidities, nor in the Apgar score at one and five minutes. Importantly, almost all the caesarean section cases were medically indicated (99\%), the cesarean by request being a tiny fraction of cases, which may not reflect the reality of outcomes in that specific population ${ }^{19}$.

It is worth mentioning a recent Chinese cohort study that evaluated more than 66,000 births, comparing outcomes related to vaginal deliveries, caesarean sections by request, caesareans with medical indication and assisted vaginal deliveries. This work is interesting because China has caesarean rates very similar to those of Brazil, close to $50 \%$. There was no difference in outcomes between patients presenting with vaginal delivery and caesarean section by request as for maternal admission to ICU, postpartum severe hemorrhage, maternal infection, damage to maternal organs, maternal thromboembolism and perinatal mortality. In fact, there were no maternal deaths in the study, proving that this outcome is very rare and difficult to assess. Cesarean section by request was related to less trauma to the neonate at birth, neonatal infection, hypoxic-ischemic encephalopathy and meconium aspiration. On the other hand, vaginal delivery was associated with less neonatal respiratory disorders $(0.4 \%$ vs. $0.6 \%$ ). The study concluded that the results were similar between these two types of delivery (vaginal and caesarean section by request), but still stated that vaginal delivery was safer. The results of assisted vaginal births and intrapartum caesarean sections were worse than vaginal deliveries or caesarean sections by request ${ }^{20}$.

Another study arising from a Danish cohort assessed almost 400,000 births and compared intention of vaginal delivery with cesarean intent, showing less severe maternal bleeding with caesarean section, the proxy of that finding being a smaller amount of red blood cell transfusion in the group submitted to intended cesarean section ${ }^{21}$

Nonetheless, in light of current evidence, one should not perform caesarean section for the prevention of cerebral palsy. Although there is evidence that caesarean reduce neonatal encephalopathy rates ${ }^{22}$, many of these cases are mild to moderate and usually do not develop into cerebral palsy ${ }^{23}$. Only $20-30 \%$ of cases of cerebral palsy is due to intrapartum hypoxic-ischemic events. A meta-analysis showed no statistically significant difference when comparing caesarean section to vaginal delivery regarding the risk of cerebral palsy ${ }^{24}$.

An outcome that is highly valued by women when requesting elective cesarean section as reported by physicians' medical experience relates to pelvic dystopias and sexual dysfunction. Vaginal delivery is associated with an increased risk of pelvic organ prolapse and this risk is higher the more vaginal deliveries occur ${ }^{25}$. This risk is due to damage to the pelvic floor muscles, which are increased in cases of prolonged second period, macrosomic fetuses and use of forceps ${ }^{26}$. A cohort study that evaluated the sexual function of more than 200 women showed decreased desire and lubrication 12 weeks after birth in vaginal delivery, and only decreased desire in cesarean section ${ }^{27}$. However, there was no significant difference between the two delivery routes, which is similar to other studies that show no difference in sexual function ${ }^{28}$. On the other hand, after application of questionnaires to assess sexual function, patients undergoing caesarean sections showed better results when compared with vaginal delivery, and those that were subjected to forceps delivery showed the worst results ${ }^{29}$. Patients with vaginismus are more likely to deliver through cesarean and when the birth takes place vaginally, there is a greater chance of perineal lacerations ${ }^{30}$.

Due to the already described reasons, vaginal delivery is related to higher rates of urinary and fecal incontinence. A study published in the New England Journal of Medicine evaluating more than 15,000 women showed that nulliparous women had lower risk for this outcome 
than those who had already given birth, and the risk was higher for urinary incontinence among women with vaginal delivery when compared with patients undergoing cesarean section. Interesting is the caution at the conclusion of the study, the authors stating that the finding should not be used to indicate a caesarean ${ }^{31}$.

Recently, it has been hypothesized a relationship between caesareans and allergic disorders and asthma. A recent meta-analysis showed an increased risk of about $20 \%$ in infants delivered via caesarean section, either elective or emergency. The increase in asthma cases may have, as one of the factors, the increasing overall rates of cesarean sections ${ }^{32}$. Not only asthma, but also several other autoimmune diseases have been growing in recent years, coinciding with the increase in caesarean section rates. Some authors hypothesize that it may be due to the different microbial colonizations resulting from vaginal deliveries and caesarean sections in the newborn sterile intestinal tract soon after birth ${ }^{33}$.

Although it is commonly reported that elective caesarean section has a higher cost than vaginal delivery, studies are conflicting about it and, if there is any difference, it is very small ${ }^{34}$. Often, managers use this argument out of the limelight to justify the need to reduce caesarean section rates. In public health, surely this is an important fact that should be openly discussed with society. A recent study that evaluated 30 articles that dealt with this subject found no superiority of cost in different routes of delivery ${ }^{35}$. In Brazil, this may be because the need to reduce the doctor's presence during childbirth, since the cost of training and hiring a doctor is much larger than of the other professionals able to perform the delivery, although only the doctor has the training and ability to resolve any complications that may arise in a physiological and unpredictable event such as birth.

An undoubted advantage of the cesarean section is the absence of pain during childbirth. This is the reason given by many Brazilians for their choice. Although non-pharmacological methods are advocated to pain relief, the evidence shows no real benefit, them having little or no effect in relieving algic perception ${ }^{36}$. Besides, the Brazilian public health system rarely provides effective analgesia for vaginal delivery.
Recently, childbirth-related issues in Brazil have been subjected to a polarization between large part of obstetricians and medical societies and activists from feminist movements advocating vaginal delivery that work at government agencies.

Recently, the Oswaldo Cruz Foundation - Fiocruz, an institution of the Brazilian Ministry of Health, released a survey, which was propagated with great emphasis in the media, giving rise to a series of articles in the its own scientific publication, the Reports in Public Health $^{37}$. The main conclusion of the study that evaluated a cohort with more than 20,000 women was that the cesarean rate reached levels much higher than the desired by women in early pregnancy in the private and public sectors. The reason given for almost half of the women was the fear of pain. Oddly, two reasons really heard by obstetricians in Brazil by women that prefer cesarean section were not even mentioned: fear of future sexual dysfunction and fear related to the schedule for the delivery by their doctors. The scheduling issue becomes important in a scenario in which there are fewer beds of private hospitals, not to mention the case in public health. The study brings several statements that are questionable from the scientific point of view, such as the report that the preference for vaginal delivery was not supported or encouraged by the professionals and that the fact that $80 \%$ of pregnant women in the private sector are accompanied by the same doctor in pre natal and delivery suggests an advice favorable to cesarean, and that the professionals' attitude towards cesarean is also influenced by financial and economic convenience. The text also suggests the possibility of biased counseling, and that women in the private sector are led to decide on a caesarean and the public sector ones are not supported in their decision for vaginal delivery in late pregnancy. These are very blunt statements that require more robust evidence to be contemplated in a scientific study. It is vital for Brazil to have research that deepens this issue without ideological biases and, preferably, independently of public support, not to generate suspicion of biased results, favorable to managers. Research of this nature and importance should be submitted to publications unrelated to the institutions 
where the researchers work, to avoid any questions of possible conflicts of interest.

\section{CESAREAN BY REQUEST: ETHICAL AND BIOETHICAL ASPECTS}

Cesarean section by maternal request or without medical indication is defined as the first caesarean section performed before start of labor and made in the absence of maternal and fetal indications ${ }^{38}$.

Here it is worth to exercise some thinking in the field of Principialist Bioethics, which uses as theoretical reference four well-known and widespread principles: Beneficence, Non-Maleficence, Justice and Autonomy.

The principle of autonomy has, in this approach, a very special relevance, since it is a presupposition for human dignity. It is essential to quote the famous words of John Stuart Mill (1806-1883) which is the mainstay in the definition of autonomy: "Over himself, over his own body and mind, the individual is sovereign". To Edmund Pellegrino: "To violate someone's autonomy is to violate the dignity of the human being. The question is how to resolve conflicts without subjugating the other, since respect for autonomy should be reciprocal between doctor and patient. If the patient takes a free, valid and non-coercive decision on not to use a particular treatment, he/she must be respected. However, he/she does not have the right to micromanage the physician's decision: one cannot expect the professional's morality or personal integrity to be violated" 39 .

Full autonomy is effectively exercised in situations where there are no external factors that may interfere with or influence the pregnant woman's decision on the route of birth. We must consider that autonomy should be preserved not as a leading principle of the Bioethics discipline but as an expression of free and informed will of the human being. For the autonomy of the pregnant woman to be respected, the doctor should listen carefully to every woman regarding their values, doubts and fears, and value the opinion of each pregnant woman about her future child's delivery, without influencing her based in the doctor's personal convictions or worse, based on personal interests ${ }^{40}$.
The clarification should be made based on the best available evidence and all questions answered to the patients. It is also important to take into account the principle of distributive justice, related to the equitable and fair allocation of financial resources that are reserved to Health and which always increase when new technologies are incorporated.

In the private sector, the cesarean section rates are over $90 \%$ and reflect the care provided to clients with greater purchasing power, more informed and with higher education index. Women who choose caesarean section in private hospitals do so because of their own autonomy and not under the influence of the treating physician. Quite differently, pregnant women seeking the public sector are subjected to the routines of the service, not having the right to choose the route of birth of their own child and being forced to give birth to their children vaginally unless provided with money to pay for the caesarean section in the supplementary health network.

In the reasoning of the bureaucrats, vaginal delivery is better because it's natural. They impute to doctors the taint of authoritarian and to women undergoing cesarean section the stigma of submissive, uninformed and uncritical to the point of passively accepting the procedure. From another perspective, we can say that authoritarianism is to impose underprivileged pregnant women to give birth vaginally when they do not wish to do so. To enforce the mode of delivery for pregnant women in Brazil's Unified Health System is to violate the right to freedom and to self-determination.

Autonomy implies the right to choose, which must be based on information provided in a transparent, clear and true way by responsible and committed professionals who have an ethical obligation to make pregnant women competent to make a choice. Faced with a request of the pregnant woman to carry out a caesarean section, Minkoff et al. opines that the doctor must answer through an extensive, informed and agreed process with the suggestion that the woman reconsider her request to ensure that their autonomy is being formally exercised. In such cases, meeting the patient's request is ethically acceptable ${ }^{41}$.

In 2008, the members of the Regional Council of Medicine of Rio de Janeiro approved an Opinion in 
favor of pregnant women to choose the type of delivery that they best see fit. The text of the rapporteur refers to Articles 48 and 56 of the Code of Medical Ethics, which assert to be sealed to the doctor: "Article 48. Exercise your authority in order to limit the patient's right to freely decide on his/her person or well-being [....]. Article 56. Disregarding the patient's right to freely decide on the implementation of diagnostic or therapeutic practices, except in cases of imminent danger to life". In conclusion, the rapporteur of the Opinion 190/08 believes that the cesarean by request is ethical as long as the decision is shared by the physician/staff and patient/family and this is considered the best option, after having exhausted all related alternatives. In the last paragraph, it also highlighted: "[....] for the ethical choice should be considered the budgetary conditions of the service so as not to harm other patients". This Opinion is important because it provides legal security to the doctor to perform a caesarean by request of the woman without having to "invent" diagnostics, then committing the crime of defrauding information in medical records.

In April 2015, the National Commission for Incorporation of Technologies in the Unified Health System of Brazil, released a document for consultation of the population and various entities that concluded the acceptance of caesarean section by maternal request ${ }^{42}$.

Also in 2015, the National Agency for Supplementary Health launched the new rules to stimulate vaginal delivery and reduce unnecessary caesarean sections. With the entry into force of the Normative Resolution No. 368, the operators of health plans, where required, shall disclose the percentage of cesarean procedures and vaginal deliveries by the clinic and doctor. They are also required to provide the Maternity Card and Newsletter to pregnant women, which shall contain the record of all prenatal care, and require obstetricians to use the partograph. The initial understanding was that doctors would not be paid in cases of caesarean section without medical indication. After enormous controversy when women and obstetricians pressured managers to ensure the autonomy of pregnant women, it was established that the mother could opt for caesarean section without medical indication through a free and informed consent.
The clarification should be made based solely on the best available evidence and all questions answered to the patients. It is also important to take into account the public issues related to costs and logistics caused by massification of health technologies.

In some sense, it is up to the State to ethically exhibit all of these issues for the population with the adoption of measures and the dissemination of data that is reliable and accessible to the population. It is important to remember that the private sector has rates of more than $90 \%$ of caesareans, showing that the autonomy of these women is imperatively respected and that the in the public sector the wishes of pregnant women are subordinate to work routines, which limits the their autonomy.

The claim that doctors interfere in pregnant women's delivery choice is flawed, as women who opt for caesarean belong to the higher social classes.

This is a universal debate and it is important to note that even in Nordic countries, bearing very low rates of caesareans and actively pursuing vaginal delivery, cesarean indication have grown motivated by cultural issues and by the women's fear related to labor pains ${ }^{43}$.

In fact, even the World Health Organization, in a recent document, abandoned the goal of $15 \%$ of cesareans that was propagated since 1985 and started aiming caesareans made only with indication, independent of goals ${ }^{44}$. There is no more developed country in the world that has rates lower than the $15 \%$ of caesareans, for so long propagated.

It is important to note that there are several countries with health indicators higher than those recorded in Brazil that have similar rates for caesarean sections, such as Italy, Chile, Cyprus, South Korea, etc. An ecological study published in the Journal of the American Medical Association (JAMA) at the end of 2015 covering 194 countries showed that caesarean section rates of $19 / 100,000$ live births showed lower maternal and neonatal mortality, concluding that the rates previously recommended by $\mathrm{WHO}$ for cesarean sections would be very low ${ }^{45}$.

\section{FINAL CONSIDERATIONS}

The authors of this work insist, without any fear, that cesarean section should be indicated whenev- 
er there is any indication or threat of harm to the maternal and fetal binomial. If in earlier times "labor death" was a fact of life, nowadays it is inconceivable and unacceptable the death of a mother due to pregnancy-delivery-postpartum.

The assertion that vaginal delivery is better because it is "natural" can not and should not be taken to the last consequences under the risk of huge misfortune.
The best form of birth is the safe one. To provide every pregnant woman with the right to choose her child's mode of delivery is to intercede for her autonomy, granting her respect and dignity guarantee.

Should the pregnant woman wish an elective caesarean, once respected her autonomy, the obstetrician should realize it when elapsed the 39 weeks of gestation to ensure the best perinatal results to the newborn.

R E S U M O

A cesariana a pedido materno é aquela realizada em uma gestante sem indicações médicas e sem contraindicação para tentativa do parto vaginal. Existe grande controvérsia sobre a realização da cesariana a pedido. Riscos potenciais da cesariana a pedido incluem complicações em gravidezes subsequentes, tais como: rotura uterina, placenta prévia e acretismo. Potenciais benefícios da cesariana a pedido englobam um menor risco de hemorragia pós-parto na primeira cesariana e menos complicações cirúrgicas quando comparada ao parto vaginal. A cesariana a pedido jamais deve ser realizada antes de 39 semanas.

Descritores: Gestantes. Parto. Cesárea.

\section{REFERENCES}

1. Hogan MC, Foreman KJ, Naghavi M, Ahn SY, Wang M, Makela SM, et al. Maternal mortality for 181 countries, 1980-2008: a systematic analysis of progress towards Millenium Development Goal 5. Lancet. 2010 Apr [cited 2010 Apr 23];375(9726):[about 14 p.] Available from: http://www.thelancet.com/journals/ lancet/article/PIIS0140-6736\%2810\%2960518-1/ fulltext?\&elsca1=WB-TLO\&elsca2=email\&elsca3=segment

2. Eckstein I. Ministério da Saúde e ANS publicam regras para estimular parto normal na saúde suplementar. 2015 Jan 06 [citado 2015 Fev 15]. In: Ministério da Saúde. Blog da Saúde [Internet]. Brasília: Ministério da Saúde. C2015 -. [about 1 screen]. Disponível em: http://www.blog.saude.gov.br/34963-ministerio-dasaude-e-ans-publicam-regras-para-estimular-partonormal-na-saude-suplementar

3. Laboissière P. (25 Maio, 2012). Mortalidade materna no Brasil teve queda de $21 \%$ de 2010 para 2011 UOL Notícias. Retirado de: http://noticias.uol.com.br/ saude/ultimas-noticias/redacao/2012/05/25/mortalidade-materna-no-brasil-teve-queda-de-21-de-2010para-2011.html

4. Xie RH, Gaudet L, Krewski D, Graham ID, Walker MC,
Wen SW. Higher cesarean delivery rates are associated with higher infant mortality rates in industrialized countries. Birth 2015;42(1):62-9.

5. O’Dwyer V, Hogan L, Farah N, Kennelly MM, Fitzpatrick C, Turner MJ. Maternal mortality and the rising cesarean rate. Int J Gynaecol Obstet. 2012;116(2)162-4.

6. Mylonas I, Friese K. The indications for and risks of elective cesarean section. Dtsch Arztebl Int. 2015;112(2930):489-95.

7. Hannah M, Hannah W, Hodnett E, Chalmers B, Kung R, Willan A, et al. Outcomes at 3 months after planned cesarean vs planned vaginal delivery for breech presentation at term: the international randomized Term Breech Trial. JAMA. 2002;287(14):1822-31.

8. Sociedade Brasileira de Pediatria; Sociedade Brasileira de Genética Médica; Federação Brasileira de Associações de Ginecologia e Obstetrícia. Projeto Diretrizes. Recém-nascido macrossômico. Brasília: AMB; CFM; 2011.8 p.

9. Tita AT. When is primary cesarean appropriate: maternal and obstetrical indications. Semin Perinatol. 2014;36(5):324-7.

10. Lumbiganon $P$, Laopaiboon $M$, Gülmezoglu $A M$, Souza JP, Taneepanichskul S, Ruyan P, et al. Method of delivery and pregnancy outcomes in Asia: 
the WHO global survey on maternal and perinatal health 2007-08. Lancet. 2010;375(9713):490-9. Erratum in: Lancet. 2010;376(9756):1902.

11. Souza JP, Gülmezoglu AM, Lumbiganon P, Laopaiboon M, Carroli G, Fawole B, et al. Caesarean section without medical indications is associated with an increased risk of adverse short-term maternal outcomes: the 2004-2008 WHO Global Survey on Maternal and Perinatal Health. BMC Med. 2010;8:71.

12. Lavender T, Hofmeyr GJ, Neilson JP, Kingdon C, Gyte GM. Caesarean section for non-medical reasons at term. Cochrane Database Sys Rev. 2006;3: CD004660.

13. Visco $A G$, Viswanathan $M$, Lohr KN, Wechter ME, Gartlehner G, Wu JM, et al. Cesarean delivery on maternal request: maternal and neonatal outcomes. Obstet Gynecol. 2006;108(6):1517-29.

14. Ecker J. Elective cesarean delivery on maternal request. JAMA; 2013;309(18):1930-6.

15. Nice Guidelines. Cesarean Section [Internet]. London (UK): National Institute for Health and Clinical Excellence. c2011 [update 2012 Aug 20]. Available from: http://www.nice.org.uk/guidance/CG132

16. van Dillen J, Zwart JJ, Schutte J, Bloemenkamp KW, van Roosmalen J. Severe acute maternal morbidity and mode of delivery in the Netherlands. Acta Obstet Gynecol Scand. 2010;89(11):1460-5.

17. Curtin SC, Gregory KD. Maternal morbidity for vaginal and cesarean deliveries, according to previous cesarean history: New Data from the Birth Certificate, 2013. Natl Vital Stat Rep. 2015;64(4):1-13.

18. Zuarez-Easton S, Shalev E, Salim R. Trend in major neonatal and maternal morbidities accompanying the rise in the cesarean delivery rate. Sci Rep. 2015;5:12565.

19. Geller E, Wu JM, Jannelli ML, Nguyen TV, Visco AG. Neonatal outcomes associated with planned vaginal versus planned primary cesarean delivery. J Perinatol. 2010;30(4):258-64.

20. Liu X, Landon MB, Cheng W, Chen Y. Cesarean delivery on maternal request in China: what are the risks and benefits? Am J Obstet Gynecol 2015;212:817.e1-9.

21. Holm C, Langhoff-Roos J, Petersen KB, Norgaard $A$, Diness BR. Severe postpartum haemorrhage and mode of delivery: a retrospective cohort study. BJOG. 2012;119(5):596-604.

22. Badawi N, Kurinczuk JJ, Keogh JM, Alessandri LM, O'Sullivan F, Burton PR, et al. Intrapartum risk factors for newborn encephalopathy: the Western Australian case-control study. BMJ. 1998;317(7172):1554-8.

23. Douglas-Escobar M, Weiss MD. Hypoxic-ischemic encephalopathy: a review for the clinician. JAMA Pediat. 2015;169(4):397-403.

24. O'Callaghan M, MacLennan A. Cesarean delivery and cerebral palsy a systematic review and meta-analysis. Obstet Gynecol. 2013;122(6):1169-75.

25. Yeniel AÖ, Ergenoglu AM, Askar N, Itil IM, Meseri R. How do delivery mode and parity affect pelvic organ prolapse? Acta Obstet Gynecol Scand. 2013;92(7):847-51.

26. Shek K, Dietz H. Intrapartum risk factors of levator trauma. BJOG. 2010;117(12):1485-92.

27. Eid MA, Sayed A, Abdel-Rehim R, Mostafa T. Impact of the mode of delivery on female sexual function after childbirth. Int J Impot Res. 2015;27(3):118-20.

28. Yeniel AO, Petri E. Pregnancy, childbirth, and sexual function: perceptions and facts. Int Urogynecol J. 2014;25(1):5-14.

29. Safarinejad MR, Kolahi AA, Hosseini L. The effect of the mode of delivery on the quality of life, sexual function, and sexual satisfaction in primiparous women and their husbands. J Sex Med. 2009; 6(6):1645-67.

30. Möller L, Josefsson A, Bladh M, Lilliecreutz C, Sydsjö $G$. Reproduction and mode of delivery in women with vaginismus or localised provoked vestibulodynia: a Swedish register-based study. BJOG. 2015;122(3):329-34.

31. Rortveit G, Daltveit AK, Hannestad YS, Hunskaar S: Norwegian EPINCONT Study. Urinary incontinence after vaginal delivery or cesarean section. N Engl J Med. 2003;34810:900-7.

32. Huang $L$, Chen Q, Zhao $Y$, Wang W, Fang F, Bao $Y$. Is elective cesarean section associated with a 
higher risk of asthma? A meta-analysis. J Asthma. 2015;52(1):16-25.

33. Neu J, Rushing J. Cesarean versus vaginal delivery: long-term infant outcomes and the hygiene hypothesis. Clin Perinatol. 2011;38(2):321-31.

34. D'Souza R. Caesarean section on maternal request for non-medical reasons: putting the UK National Institute of Health and Clinical Excellence guidelines in perspective Best Pract Res Clin Obstet Gynaecol. 2013;27(2):165-77.

35. Fahy M, Doyle O, Denny K, McAuliffe FM, Robson M. Economics of childbirth. Acta Obstet Gynecol Scand. 2013;92(5):508-16.

36. Jones L, Othman M, Dowswell T, Alfirevic Z, Gates S, Newburn $M$, et al. Pain management for women in labour: an overview of systematic reviews. Cochrane Database Syst Ver. 2012;3:CD009234.

37. Domingues RMSM, Dias MAB, Nakamura-Pereira $M$, Torres JA, d'Orsi E, Pereira APE, et al. Processo de decisão pelo tipo de parto no Brasil: da preferência inicial das mulheres à via de parto final. Cad Saúde Pública. 2014; 30 Suppl 1:S10116.

38. American College of Obstetricians and Gynecologists. ACOG committee opinion no. 559: Cesarean delivery on maternal request. Obstet Gynecol. 2013;121(4):904-7.

39. Pellegrino E. O bem estar do paciente deve suplantar os interesses do médico [entrevista]. Rev Ser Médico. 2011; 56:4-8.
40. Barcellos L, de Souza AOR, Machado CAF. Cesariana: uma visão bioética. Rev Bioética. 2009;17(3):497-510.

41. Minkoff H, Powderly KR, Chervenack F, McCullough LB. Ethical dimensions of elective primary cesarean delivery. Obstet Gynecol. 2004;103(2):387-92.

42. Diretrizes de Atenção à Gestante: a operação cesariana. Relatório de recomendação. Brasília: Conitec. Comissão Nacional de incorporação de tecnologia no SUS; 2015.

43. Dweik D, Sluijs AM. What is underneath the cesarean request? Acta Obstet Gynecol Scand. 2015;94(11):1153-5.

44. Declaração da OMS sobre Taxas de Cesáreas [Internet]. Geneva, Switzerland: World Health Organization. Disponível na Internet: http://apps.who.int/iris/ bitstream/10665/161442/3/WHO_RHR_15.02_por. pdf

45. Molina G, Weiser T, Lipsitz S, Esquivel M, UribeLeitz T, Azad T, et al. Relationship between cesarean delivery rate and maternal and neonatal mortality. JAMA. 2015;314(21):2263-70.

Received in: 01/03/2016

Accepted for publication: 09/06/2016

Conflict of interest: none.

Source of funding: none.

\section{Mailing address:}

Raphael Câmara.

E-mail: raphaelcmparente@hotmail.com 